\title{
Marcus Barros fala sobre meio ambiente e doenças tropicais na Amazônia
}

\author{
Marcus Barros talks about the environment and tropical \\ diseases in the Amazon
}

Entrevista a

Stella Oswaldo Cruz Penido Casa de Oswaldo Cruz/Fundação Oswaldo Cruz

Av. Brasil, 4365 - Prédio do Relógio 21040-900 Rio de Janeiro - RJ

Brasil

socpenid@coc.fiocruz.br

Apresentação de

Ruth B. Martins

Casa de Oswaldo Cruz/Fundação Oswaldo Cruz

Av. Brasil, 4365 - Prédio do Relógio 21040-900 Rio de Janeiro - RJ

Brasil

rmartins@coc.fiocruz.br
BARROS, Marcus. Marcus Barros fala sobre meio ambiente e doenças tropicais na Amazônia. Entrevista a Stella Oswaldo Cruz Penido; apresentação de Ruth B. Martins.

História, Ciências, Saúde-Manguinhos, Rio de Janeiro, v.14, suplemento, p.291-302, dez. 2007.

Marcus Barros fala sobre a influência que as doenças tropicais exerceram em sua escolha pela carreira de médico. Conta várias histórias, como a da mudança da família do Alto Juruá para Manaus, fugindo da malária e de outras febres. Diz ser fundamental adotar a homeopatia, a acupuntura e os conhecimentos e práticas indígenas na cura de doenças. Relata as atividades que exerceu como presidente do Instituto Brasileiro do Meio Ambiente e dos Recursos Naturais Renováveis

(Ibama), visando a prevenção e o combate a essas doenças, bem como as medidas de controle ambiental que adotou: a repressão ao desmatamento, levando à sua diminuição nos últimos anos, e a prisão de funcionários públicos corruptos.

PALAVRAS-CHAVE: doenças tropicais; Amazonas; malária; índios; desmatamento; meio ambiente; Instituto Brasileiro do Meio Ambiente e dos Recursos Naturais Renováveis.

BARROS, Marcus. Marcus Barros talks about the environment and tropical diseases in the Amazon. Interviewed by Stella Oswaldo Cruz Penido; introduction by Ruth B. Martins. História, Ciências, Saúde-Manguinhos, v.14, supplement, p.291-302, Dec. 2007.

Marcus Barros talks about how tropical diseases influenced his decision to study medicine. He tells a number of stories about his family, which moved from Alto Juruá to Manaus to escape malaria and other fevers. He says it is essential to adopt homeopathy, acupuncture, and other indigenous knowledge and practices in treating disease. Barros also talks about measures taken when he was president of Brazil's national environmental institute, Instituto Brasileiro do Meio Ambiente e dos Recursos Naturais Renováveis (Ibama) - all part of an effort to prevent and combat these diseases and halt deforestation and burn-offs.

KEYWORDS: tropical diseases; Amazonas; malaria; Indians; deforestation; environment; Instituto Brasileiro do Meio Ambiente e dos Recursos Naturais Renováveis. 


\section{Apresentação}

Ruth B. Martins

$\mathrm{N}$ ão foi por acaso que Marcus Barros resolveu ser médico. Desde pequeno ele ouvia histórias impressionantes, que marcaram sua família. Algumas são tristes, outras tragicômicas. Constituem o baú de lembranças do ilustre representante dos Barroso - o lado materno da família, de origem cearense. A malária ou outra febre terrível com freqüência injetam colorido especial ao enredo, roubando a cena, mas as histórias quase sempre têm final infeliz.

Há sessenta anos, Marcus Barros nasceu em Eirunepé, no alto Juruá, que se chamava então São Felipe. Oswaldo Cruz refere-se ao lugarejo no relatório da viagem que fez à região, em 1913: “em São Felipe, 800 almas... ano passado, quatrocentas mortas por malária ...". Marcus tinha um ano quando seus pais foram viver em Manaus, fugindo das endemias e de suas complicações. Uma delas aconteceu com o avô materno, que adorava festas, quando 'bebia todas'. Após uma delas, para atenuar a ressaca, em vez de sal de frutas tomou uma overdose de quinino. Essa e outras histórias influenciaram a opção de Marcus Barros pela medicina.

Infectologista, instalou e dirigiu o núcleo original da Fundação Oswaldo Cruz (Fiocruz) em Manaus, que é hoje o Centro de Pesquisa Leônidas e Maria Deane. Foi reitor da Universidade Federal do Amazonas e criou o Museu Amazônico Para a Preservação da Cultura dos Povos da Amazônia Ocidental e o Centro de Ciências do Ambiente. Dirigiu o Instituto Nacional de Pesquisas da Amazônia (Ibama). Atualmente é secretário de governo da cidade de Manaus.

Marcus Barros concedeu esta entrevista a Stella Oswaldo Cruz Penido em Brasília, em abril de 2007, pouco antes de deixar a Presidência do Ibama. Na época a imprensa veiculou uma série de notícias a respeito das graves divergências quanto à política ambiental, entre as ministras Marina Silva, do Meio Ambiente, e Dilma Rousseff, chefe da Casa Civil da Presidência da República. Lideravam elas dois grupos, e o pomo da discórdia era a visão de cada uma sobre o tipo de desenvolvimento que convém à região.

Durante a entrevista, além de destacar medidas que vinham sendo adotadas para reduzir o desmatamento - que caíra de 28 mil quilômetros quadrados, em 2005, para 13 mil, em 2006 -, Marcus Barros falou sobre movimento migratório e ocupação dos espaços, as doenças determinadas por esses migrantes e vários projetos em curso na região, como os que têm por objetivo diminuir a incidência das doenças que castigam os moradores do lugar. Em 2005, apenas a malária fez trinta mil vítimas no Amazonas.

Neste dezembro de 2007, oito meses depois de sua saída do Ibama, Marcus Barros é econômico nos comentários sobre a política ambiental em curso no país. Prefere aguardar os relatórios da terceira Reunião das Partes Para o Protocolo de Quioto (MOP3), encontro internacional que discute o aquecimento global e seus efeitos no clima planetário, para emitir opiniões a respeito do trabalho apresentado por Daniel Nepstad na Indonésia. Diz apenas que "o trabalho é serio, com rigorosa metodologia e, portanto, seus dados são honestos. Conheço seu campo de experimentação no Pará, à época em que dirigia o Instituto Nacional de Pesquisas Amazônicas (Inpa). Daniel Nepstad afirma que o ciclo vicioso desmatamento-aquecimento-queimadas provocará o desaparecimento de 55\% da cobertura vegetal da floresta até 2030, caso não sejam ampliadas as ações de desenvolvimento sustentável na região. 


“Oswaldo Cruz já
descrevia em
1913 em seu
relatório: ‘em São
Felipe, 800 almas,
ano passado 400
mortas por
malária'. Essa
mortalidade
apavorava a
família toda, e os
Barroso
começaram a
migrar para
Manaus ...”

Você acompanha nosso trabalho na Casa de Oswaldo Cruz desde o início. Em 1991, começamos o projeto Revisitando a Amazônia de Carlos Chagas - Da Borracha à Biodiversidade, quando estivemos em Eirunepé, no Alto Juruá, sua cidade natal. Fale da sua infância, das influências em sua escotha pela medicina.

Meus avós chegaram ao Juruá vindos do Nordeste. Esse é o meu lado Barroso, sou Marcus Luiz Barroso Barros. Esse lado Barroso é nordestino, é cearense, do lado litorâneo do Ceará. Eles migraram de um lugar chamado Itapipoca, para o Alto Juruá. E o final da vida de meu avô, pai da minha mãe, tem influência sobre a minha carreira. Eirunepé se chamava São Felipe e, como Oswaldo Cruz já descrevia em 1913 em seu relatório, “em São Felipe, 800 almas, ano passado 400 mortas por malária". Essa mortalidade sempre nos apavorava, a família toda, e os Barroso começaram a migrar. Nessa migração viemos para Manaus. Meus avós ficaram lá no Juruá, e eu vim muito cedo; quando eu tinha um ano, a gente teve que vir embora para a cidade.

Meu avô tem uma história no final da vida dele que influenciou minha vida. Ele era dono de um barracão no Juruá e a grande festa - contavam minha avó e minha mãe - era quando chegavam os regatões. Chegavam os regatões, era muita novidade, e meu avô gostava muito de cachaça. Ele tomou naquela noite, alegre e satisfeito, aquela festa! Como mostra a minissérie Amazônia: homem dançando com homem, porque as mulheres eram poucas. Por esses relatos, desde a minha infância, soube que meu avô tinha um costume: quando tomava todas, ele ia para o barracão e pegava um pouco de sal de frutas Eno. Mas, também naquela época, havia uma endemia de malária muito expressiva. E minha avó pegava o quinino, que vinha em pó, para que se fizessem os comprimidos ali em casa mesmo, e quando terminou o sal de frutas Eno ela colocou o quinino dentro do frasco, mas não rotulou e deixou lá, para depois fazer as hostiazinhas do remédio. Depois da cachaçada, meu avô confundiu o quinino com sal de frutas Eno e fez uma dose forte de quinino. O quinino é tóxico para o nervo ótico, e com aquela superdosagem ele ficou cego.

Isso traumatizou muito minha família, porque minha mãe, mocinha, já morava em Fortaleza e teve que ir resgatar o meu avô cego no Alto Juruá. Você imagina o relato dela. Isso foi durante a Segunda Guerra Mundial: os navios comboiados, a vinda no escuro, a viagem de trinta dias de Fortaleza até o Alto Juruá para resgatar meu avô. E no percurso - outro dado das doenças infecciosas duas primas morreram de febre tifóide e foram enterradas na várzea do Amazonas.

Essa epopéia toda do extrativismo, do declínio do extrativismo, depois o movimento migratório dos Barroso para Manaus, isso me marcou muito. As endemias marcaram sempre a minha vida. Quando 
houve oportunidade comecei a estudar as chamadas doenças tropicais. E claro que depois entendi que as doenças tropicais não eram estritamente tropicais. O clima e o meio ambiente eram alguns dos determinantes disso, mas havia outras causas. As condições econômicas eram marcantes. Já adulto, depois da pós-graduação comecei a valorizar o que nós chamamos de 'espaço e doença'. E aí entraram outros fatores no meu entendimento sobre combate ou controle das doenças infecciosas: se a gente não fizesse uma abordagem multifatorial, se as causas não fossem entendidas como múltiplas, nós não conseguiríamos controlar a malária, por exemplo.

Muito do que sei sobre a história da saúde no Amazonas aprendi com você. E você sempre fala sobre a importância dos movimentos migratórios na ocupação do espaço e as doenças determinadas por eles. Você pode nos falar desses movimentos sob uma perspectiva histórica?

A borracha, como você sabe, foi um dos marcos fundamentais. Houve esse movimento, a industrialização, e a necessidade de se pagar as dívidas com essa riqueza natural. O Amazonas sempre foi o último bastião, sempre foi o celeiro: "vamos lá na Amazônia". Mas há um detalhe nesse processo econômico, que se chama homem. E aí a coisa pega. Porque os movimentos migratórios começaram através de grandes projetos. O que é o PAC hoje, o Programa de Aceleração do Crescimento? É o projeto econômico para elevar o PIB e distribuir renda. E houve, vamos chamar assim, o PAC do século XIX da Amazônia, um PAC reduzido, focal, chamado Madeira-Mamoré. E foram surgindo outras tentativas focais, não tão amplas como o atual PAC, mas grandes projetos na Amazônia. Para esses grandes projetos, foram sempre necessários grandes movimentos migratórios. O professor Samuel Pessoa, um parasitologista da minha geração, dizia, numa de suas publicações, que veio para a Amazônia, com a Madeira-Mamoré, um triste rebanho humano, homens de todo o mundo. Você imagina o que significa a construção da Madeira-Mamoré: juntando aquele e esse cadinho trabalhando na destruição, mesmo que focal, do ecossistema amazônico... Especificamente no caso da MadeiraMamoré, em cima de um charco, em cima de uma área totalmente alagada, o que aconteceu aí? Destruição.

A endemia surgia com todo vigor, junto a outros componentes da ocupação desordenada do espaço como a violência e as intoxicações descritas no relatório de Oswaldo Cruz, causadas pelo clostrídio do botulismo, contraído nas latas de conserva, que se furava para reaproveitar. E o homem tentando superar todas essas dificuldades, trazendo os grandes sanitaristas da época, liderados por Oswaldo Cruz, para viabilizar o movimento migratório. Passaram por Manaus àquela época mais de 150 mil nordestinos. O movimento migratório, nesse ecossistema, com a ocupação desordenada, 
"Esse trabalho

inclui a infância

escrava das

carvoarias do

complexo de

Carajás. E o

homem é tratado

como bicho, sem

carteira assinada.

É outro processo

migratório muito

mais denso, e

cabe ao Estado

hoje intervir e

reprimir

violentamente." por mais que tivesse o Hospital da Candelária, a preocupação dos sanitaristas ingleses, as experiências trazidas do Panamá ou de outros grandes projetos, estas iniciativas sempre eram pequenas em relação ao grau de agressão à natureza e à sobrevivência do homem vindo de vários lugares. Depois disso, entra em declínio o movimento migratório nesse processo de desenvolvimento.

A Segunda Guerra é um marco importante. Eu me lembro de um casal de entomologistas - os Causey - que veio da Fundação Rockefeller e ajudou a fundar o Instituto Evandro Chagas, criado para tentar ajustar o nosso potencial exportador de borracha durante a guerra, para ver se nós conseguíamos sobreviver à malária.

Você está falando das expedições científicas do começo do século XX e do surgimento das instituições médico-científicas. Você teria hoje uma visão crítica dessas expedições, um olhar crítico desse movimento civilizatório?

As expedições eram reparadoras. Hoje, do ponto de vista tecnológico, a gente tem instrumentos que não são apenas de reparação do dano - são instrumentos preventivos. Há estratégias de proteção ambiental que estabelecem claramente o que se pode e o que não se pode fazer. Como presidente do Ibama* sei que a política de licenciamento ambiental, quando se vai fazer um grande empreendimento, já diz claramente qual será o impacto - inclusive do ponto de vista da saúde pública. Essa é uma grande diferença. $\mathrm{O}$ Ibama, que é o órgão executivo do meio ambiente, inviabiliza determinadas obras. Se ele existisse no final do século XIX, afirmaria com relação à estrada de ferro Madeira-Mamoré: "apesar de importante, de trazer a produção gomífera da Bolívia para o resto do mundo etc., essa estrada é inviável porque vai matar muitas almas". Não teríamos só as instituições a produzir ciência no local e tentando reparar o dano: "toma esse comprimido de quinino para poder ir pra frente, e quem não tomar está fora". Era o poder de polícia tentando viabilizar a obra.

Hoje já existem outros parâmetros. Apesar de ainda, lamentavelmente, haver o trabalho escravo, que às vezes foge desse processo migratório de que falávamos. Esse trabalho inclui a infância escrava das carvoarias do complexo de Carajás. E o homem é tratado como bicho, sem carteira assinada. É outro processo migratório muito mais denso, e cabe ao Estado hoje intervir e reprimir violentamente. Ainda existe esse tipo de relação nas áreas onde há um número expressivo de neo-escravos, a influenciar no lucro das grandes empresas. No mundo globalizado, compra-se o aço obtido através da degeneração da mata primária na Amazônia ou de trabalho escravo; do contrário esse aço não tem preço competitivo e não é

\footnotetext{
* Nota do editor: Marcus foi afastado do cargo dois meses depois da entrevista.
} 
comprado. Há uma pressão internacional que beneficia quem tem esse tipo de lucro, e isso reflete na saúde do homem. Ele fica em condições sub-humanas, fragilizado com malária, febre amarela e outras endemias. Então, não é necessário o surgimento de grandes aparelhos estatais de saúde, mas sim o reforço preventivo e a valoração desse homem, que não pode ser considerado descartável. Ou seja, já não é possível mobilizar levas sucessivas de mão-deobra barata para entrar nesse mecanismo de exploração e destruição da natureza.

Ao abrir os jornais hoje, li uma notícia gratificante: um juiz de Altamira caçou mais de quatro milhões de hectares na Terra do Meio, terras griladas, de uma empresa chamada CR Almeida, com que nós passamos a vida inteira brigando para provar que aquelas eram terras públicas e griladas. Quer dizer, a Constituição de 1988 e a implantação de uma política ambiental, no que diz respeito à normatização e à legislação de crimes ambientais e a todo o marco legal, deram respaldo para a saúde humana. Ainda estamos longe do ideal, mas começou-se a criar uma transversalidade entre as ciências no modo de abordar a saúde: a saúde multivariável, que diz respeito à preservação do homem. O Estado está mais atento para evitar que esse homem adoeça.

\section{Essa ação na Amazônia chega a ser preventiva para a malária?}

Com base nos últimos dados, devo dizer que ainda está distante disso. Vamos considerar Manaus: de 2005 para 2006, eram trinta mil casos de malária, o que é muito. Um movimento migratório do leste da Amazônia, em busca de mão-de-obra no pólo industrial de Manaus, deixa escassas as mãos-de-obra do Maranhão e do Pará, estados já com certo declínio econômico. Aqui no centro da Amazônia, o que acontece? Um pólo industrial que atrai. E a vinda de imigrantes de todos os lados, até de garimpos desativados lá do norte, em São Gabriel da Cachoeira e Roraima, determina o movimento migratório para o pólo desenvolvimentista. Há uma desproporção e o governo brasileiro não consegue contornar com facilidade esse caráter preventivo, e a malária ainda cresce assustadoramente. Onde há pólos de desenvolvimento, o controle ainda está longe do ideal.

Na Presidência do Ibama você teve oportunidade de trabalhar essa transversalidade, em relação às doenças?

Muito. Demorei para entender por que fui chamado a exercer essa tarefa de presidir o Ibama. Só mesmo quando cheguei aqui, entendi a ministra e o presidente: eles queriam alguém que lutasse pelo meio ambiente e valorizasse o bem-estar do homem. Sou médico e professor, e entendi que nosso trabalho aqui é preparar o meio ambiente para o homem, e é nessa direção que estamos nos 


“Vamos
considerar
Manaus: de 2005
para 2006, eram
trinta mil casos de
malária, o que é
muito ... Onde há
pólos de
desenvolvimento,
o controle ainda
está longe do
ideal.”

ideal.” esforçando, sem prescindir da necessidade de projetos para o desenvolvimento. Alguns bloqueamos, dizendo "aqui não há viabilidade ambiental". Outros tocamos para frente, de maneira bem expressiva, e conseguimos preparar o terreno: desenvolver para o homem, levando a variável ambiental em conta. Não há romantismo nisso; há um pragmatismo incrível. É uma linha, e nós temos que nos unir porque o problema é tão grande que, sem essa transversalidade das outras disciplinas e das outras áreas, não conseguiremos dar viabilidade a projetos. Ou seja, licenciar os projetos que têm como fio o desenvolvimento econômico do ecossistema mais rico e mais frágil do mundo. Ele é nosso, está dentro do nosso espaço territorial, é uma questão de segurança nossa, mas precisamos dar conseqüência a isso e o esforço é nessa direção. Como a tarefa é hercúlea não dá para dizer que somos só nós, então chamamos todos a participar. Quer ver? Nestes dois anos reduzimos em $52 \%$ o desmatamento da Amazônia. Chegamos aqui, mas ainda falta muito. Eram 28 mil quilômetros quadrados desmatados naquele ano, reduzimos para 13 mil. Precisamos reduzir mais ainda, ao mesmo tempo em que abrimos um espaço para o desenvolvimento, mostrando áreas degradadas e abandonadas. Sabe qual é a área antropizada no sul da Amazônia, ou seja, destruída pelo homem? São 160 mil quilômetros quadrados onde precisa ser replantada a floresta. Isso é o que chamamos de "desenvolvimento sem avançar sobre a floresta amazônica". É como se tivéssemos dado os braços ali no sul [o Arco do desmatamento], quando criamos um grande mosaico de Unidades de Conservação. A imagem simbólica que faço consiste em dizer assim: "daqui não passará". Em cima da floresta, não! Nós já sabemos claramente. Daqui para baixo, aproveitem todas essas áreas, são 160 mil quilômetros quadrados, é muita coisa que já se fez degradando com pasto ou com soja, ou com corte linear e raso da floresta. Isso a política de ocupação fundiária tem que mostrar.

Hoje, nós montamos no Ibama um sistema de monitoramento que é consorciado com o Sipam (Sistema de Proteção da Amazônia), que é consorciado com o Inpe (Instituto Nacional de Pesquisas Espaciais) e com o lançamento de um novo satélite que vai surgir só para a Amazônia, o Amazônia 1. Com o Deter, que é outro sistema, podemos detectar onde está havendo desmatamento agora, em pequenas propriedades, imagine nas grandes. $\mathrm{O}$ desmatamento do sub-bosque. Sabe como é? Os mais espertos e inteligentes que os outros vão desmatando os sub-bosques e nós localizamos ali, onde está havendo aquele desmatamento, e mobilizamos a nossa ação de fiscais consorciados com os estados.

O governador Blairo Maggi transformou 10\% da Polícia Militar do Mato Grosso em Polícia Ambiental, para estar transversalmente ligado às ações do governo federal. Com isso, o sistema de proteção 
da Amazônia cresceu muito, e aí vamos poder dizer "aqui sim, aqui não". Eu posso dizer que não se constrói mais na Amazônia uma Hidrelétrica de Balbina de jeito nenhum. Você destrói dois milhões de quilômetros quadrados com aquelas áreas alagadas e produz 250 megawatts. Isso não é nada! Belo Monte, se viabilizado, vai produzir 3.500 megawatts. As duas hidrelétricas do rio Madeira, quando viabilizadas, vão produzir 6.500 megawatts. Agora o licenciamento é muito rigoroso. É um trabalho árduo, onde se discute muito, mas o desenvolvimento sustentável é a única arma que se tem para um bioma tão frágil como o da Amazônia e outros, como o marinho. Trabalhar aqui é muito interessante e, no plano pessoal, me enriqueceu muito.

E a política ambiental para um desenvolvimento sustentável nesses anos em que você está aqui?

Foi dado o passo inicial, mas a política nessa direção é muito ampla. A ministra Marina com toda a equipe traçou grandes linhas políticas para a região. Ela diz assim: "aqui é a Amazônia, não podemos ser, não devemos e não seremos contra o desenvolvimento. Mas, desenvolvimento aqui, só com sustentabilidade". Não se quer desenvolver a Amazônia só com reservas extrativistas, porque isso não é desenvolvimento. Têm que existir oportunidades para as populações tradicionais. É uma maneira de preservar as terras indígenas, que têm que ser preservadas mesmo. É da Constituição Brasileira. Essa política tem que ser efetiva lá na ponta, com o objetivo de mostrar, para os empresários e para todo o Brasil, os caminhos possíveis para o desenvolvimento. $\mathrm{O}$ que não se pode mais é repetir o que a CR Almeida fez na Terra do Meio, no Pará: ao construir a BR-163, à medida que passava a estrada, essa empresa ia grilando e ocupando as terras. Isso já não existe mais no Brasil. Muita coisa ainda precisa ser controlada, mas o marco político para o desenvolvimento desses biomas, especialmente a Amazônia, nosso governo começou a traçar e executar. E o fim deve ser o homem, mesmo.

E a micropolítica das reservas extrativistas, a demarcação das terras indígenas?

Avançou muito. Hoje a ministra Marina Silva tem um papel nessa política, porque foi a criadora, com Chico Mendes. Existe a Reserva do Juruá, a Reserva Chico Mendes. Aquela foi só a semente, hoje temos reservas extrativistas no sul da Bahia, em Santa Catarina, no mar, com as populações dos mangues. Toda a franja maranhense e a franja paraense dos manguezais estão sendo protegidas graças à população e se estão buscando alternativas de sobrevivência dignas dessas populações, através de recursos natu- 
“...O que não se pode mais é repetir o que a CR Almeida fez na Terra do Meio, no Pará: ao construir a BR163, à medida que passava a estrada, essa empresa ia grilando e ocupando as terras. Isso já não existe mais no Brasil.” rais, viabilizando no mercado esses recursos naturais. Elas foram se expandindo. Hoje, são quase cem reservas extrativistas ou propostas de reservas extrativistas a serem implantadas. Quer dizer, as pessoas e as populações foram acreditando nisso. Alguns extratores de madeira mal intencionados descaracterizaram ou tentaram descaracterizar essas reservas extrativistas para que continuassem a explorar madeira de um modo não sustentável. Isso nós combatemos com a Polícia Federal, prendemos as pessoas. Fomos obrigados a fazer uma limpeza ética na nossa própria instituição: prendemos 113 servidores do Ibama nesses quatros anos. Isso nos doeu muito. Mas algemamos as pessoas, abrimos processos, todos foram processados. Já conseguimos demitir 42 do serviço público, vamos demitir outros. Para que o aparelho também seja melhorado, tornese mais saudável, no sentido de ser exemplar no combate ao ilícito. A Polícia Federal faz isso, nós também fazemos.

Mas afinal, por que o médico vem para cá? Por que o professor universitário vem para cá? Porque o meio ambiente é o espaço desse homem. E ao criar e implantar uma política em que a agressão ambiental será mínima e o desenvolvimento será para o homem, você tem como fruto a diminuição da doença.

Como o aquecimento global irá redefinir a ação da doença na região amazônica?

Como é um ambiente que tem suas fragilidades, há que se ter cuidados importantes, pois os danos são globais. Alguns exemplos recentes: ao aquecer em 2005 as águas do Atlântico, esse aquecimento gerou um ramo superior para o sul dos Estados Unidos, formando o furacão Katrina, em Nova Orleans. O outro ramo caminhou para o sul, e isso secou a Amazônia. Vamos dizer que graças a Deus isso é um capricho da natureza, não será constante. Essas secas, sabidamente, não serão constantes na Amazônia. Eu acompanhei uma em 1963, muito expressiva, quando o rio Negro virou quase um igarapé, e a cidade flutuante localizada na frente de Manaus, e que depois foi retirada, ficou toda fora d'água. Há esse movimento cíclico das secas da Amazônia. Agora, quando muda o clima, há mudanças. Não radicais, a ponto de a Amazônia se desertificar. Não é essa a questão central, mesmo que o clima mude globalmente. Mas os impactos são naturais num bioma frágil.

O que eu chamo de 'naturais'? Vamos tomar a malária como exemplo. A malária pode aumentar se a densidade de mosquitos aumentar pelas mudanças climáticas. Não só o Anopheles darlingi, o anofelino transmissor mais expressivo da malária, o mais adaptado ao parasita para transmitir de uma pessoa a outra. Os anofelinos são muitos. As famílias dos semelhantes a esse tipo de mosquito são muitas. Eu posso antever, sem ser catastrófico, que outros anofelinos virão. O Anopheles cruzi, por exemplo, pode crescer e se expandir em 
substituição ou em acréscimo àquele anofelino clássico que transmite a malária desde as grandes endemias do século XIX. Isso pode acontecer. As outras alterações estarão sendo dadas: condições objetivas, climáticas, para que as doenças vetoriais avancem. Isso é verdade. Esse é um dos impactos que podem surgir. As doenças de veiculação hídrica podem surgir porque "são muitas Amazônias", como Minas. A Amazônia é hoje o que se chama de Amazônia Azul, a franja da Amazônia marítima que vem lá do Oiapoque, vem descendo pelo Amapá, pela costa do Pará até as franjas maranhenses. É claro que se o mar crescer um metro sobre aqueles manguezais, trará problemas. Alguns dizem que isso ajuda na renovação dos manguezais, mas há que se estudar os impactos para evitá-los ou prevenir a humanidade, os habitantes, do ponto de vista do que esses impactos geram na vida do homem. Isso não está mensurado, há suposições. E essas suposições não precisam ser encaradas do ponto de vista catastrófico, mas não se pode varrê-las para debaixo do tapete, desconhecer o potencial que elas têm de determinar mudanças na relação do homem com seus parasitas.

No alto rio Negro os pajés e benzedores participam do processo de cura não só das populações indígenas, mas também na cidade e nos centros de saúde do DSEI (Distrito Sanitário Especial Indígena) do Rio Negro. No entanto, ainda não há o reconhecimento do SUS para os pajés e benzedores. Como vocêvê isso?

Como a medicina da China, ela é de alto nível e tem uma base tradicional enorme que não se deixou de lado. Ao contrário, se incorporou. Estou fazendo sessenta anos, vi a acupuntura chegar e ser encarada de maneira preconceituosa, muita gente a deixava de lado. Hoje, a prática faz parte dos currículos das universidades e das faculdades de saúde. É uma prática popular que avança e é absorvida no SUS. A homeopatia é outro exemplo. Essas práticas tradicionais têm que ser reconhecidas nesse processo. E serão, quando nossa ignorância, autoritarismo e preconceito diminuírem em relação a elas. Todo o aparelho de Estado não tem tanta força para chegar até essa ponta como as nações indígenas, por exemplo. Até a pontinha da Amazônia.

A gente tem que entender aquela realidade histórica, de que eram os chás de quina que curavam a malária. Não era assim? Não foi a partir do jaborandi que se fizeram os colírios que ainda contornam o glaucoma? Não foi das serpentes que veio o veneno para diminuir a pressão arterial das pessoas? Não podemos perder essa perspectiva histórica: que se diminua a nossa ignorância e que tenhamos a humildade de absorver isso para inserir nos grandes sistemas. A fim de que possamos controlar os grandes males. É preciso fazer isso, e a academia precisa estar aberta para receber esses conhecimentos e absorvê-los. 
“...vi a

acupuntura

chegar e ser

encarada de

maneira

preconceituosa,

muita gente a

deixava de lado.

Hoje, a prática faz

parte dos

currículos das

universidades e

das faculdades de

saúde. É uma

prática popular

que avança e é absorvida no SUS.

A homeopatia é outro exemplo."
Quando fui reitor da Universidade Federal do Amazonas trouxe os índios para o Conselho Universitário. E trouxe um pajé, o Gabriel Gentil, como pesquisador emérito, para a Fiocruz. Ele morreu como pesquisador no Centro de Pesquisa Leônidas e Maria Deane, que ajudei a construir na Amazônia. Temos de fazer outros esforços nessa direção. O seu trabalho sobre os Baniwa é uma mostra disso: desse encontro das gerações e dos saberes. A Amazônia deve muito à Fiocruz.

No final do século XIX, as grandes viagens para a Amazônia contribuíram para o entendimento e, pelo menos, para a medicalização desse homem sofrido. Depois a Fiocruz afastou-se e só na década de 1980 retomou seu papel, ao revisitar os grandes rios. O trabalho começou com o Juruá, com vocês. E depois vieram o Negro e o Purus, a análise da biodiversidade - da borracha à biodiversidade -, foi uma retomada muito rica, e quando a Fiocruz cria uma instituição na linha de frente, que busca entender mais a Amazônia, está contribuindo. E precisa contribuir mais. A Fiocruz precisa ser mais agressiva em relação à Amazônia, nos ajudar de maneira consorciada com as instituições locais, as universidades, $\mathrm{o}$ Inpa, quebrar barreiras. De uma instituição que tem o reconhecimento mundial como a Fiocruz, esperamos respaldo, que nos ajude a ser mais sábios em relação à Amazônia. Só assim conseguiremos dominar a natureza para poder melhorar a situação da região.

Nossas relações inter-humanas avançaram muito no que eu chamo de 'retomada' no final do século passado, mas precisamos melhorar. Nós da Amazônia precisamos ser mais humildes, menos preconceituosos. Já sofremos tantas agressões nestes quinhentos anos de colonização que criamos um espírito de rejeição diante de quem chega. Eu faço essa autocrítica, reconheço: como mecanismo de defesa, temos isso mesmo. E as pessoas que chegam têm que ter menos preconceito em relação à Amazônia.

Menos arrogância também.

É. O termo que eu buscava era esse. O termo mais suave: menos arrogância. Tem que conhecer os nossos saberes. Tem que saber que nós estamos lá há muitos séculos e desse consórcio, desse amálgama vai surgir uma Amazônia muito mais legal, pelo peso dessas instituições e pelo peso das instituições da região. Existem instituições com 150 anos na Amazônia, como o Instituto Goeldi, por exemplo, e eu acho que principalmente através da geração do conhecimento nós seremos mais livres e teremos a soberania sobre a região. Não se tem soberania guardando fronteiras só com tropas. Isso é uma parte do processo. Nem com satélites só, que são outro instrumento.

Soberania se faz com o homem educado, o homem produtor de conhecimento. Educado no sentido mais amplo de educação. É dis- 
so que nós falamos: da macropolítica, do desenvolvimento, da ocupação racional do espaço. Da ocupação com respeito à vida, diferente dessa ocupação de só entrar, tirar. Não é possível que não tenhamos aprendido com a história. Nós só vemos os subprodutos: a prostituição, o trabalho escravo, a pobreza, a marginalização, a exclusão. E será que não aprendemos?

E a saúde é multifatorial, mesmo. Saúde é uma parte importante do desenvolvimento. Insira essa variável para o desenvolvimento orgulhar a todos os amazônidas.

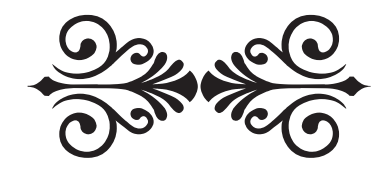

